\title{
Studies on Dynamic of Dominant Populations in Dinghushan Forest in Succession
}

\author{
PENG SHAOLIN FANG WEI \\ South China Institute of Botany, Academia Sinica. Guangzhou 510650 \\ (Received December 13, 1994: Revised March 28, 1995)
}

\section{ABSTRACT}

The forest successional process is characterized by the dynamic of dominant populations in different successional stages. In this paper, the dynamic of main dominant populations in the succession process of Dinghushan forest has been studied systematically: Four communities have been selected to represented four different stages which are a sere. The dynamics of five dominant populations including one conifer (Pinus massoniana), two heliophytes (Castanopsis chinensis and Schima superba) and two mesophytes (Cryptocarya chinensis and Cryptocarya concinna) were studied. Their niche breadths, population patterns, interspecific associations and niche overlaps in 38 year's change have been analyzed. The results show that the different characteristics of dynamics and distribution of conifer. heliophyte and mesophyte populations in different succession periods reveal the position and role of each dominant population in every succession stages. The succession mechanism were revealed with population dynamic analysis.

Key words Dinghushan, forest succession, dynamic, dominant population

\section{INTRODUCTION}

The study on succession is the core of the vegetation dynamics research. Population dynamics is the key to reveal the succession process (Knapp, 1984; West, et al. , 1981).

Dinghushan forest is evolving to the most prevailing climax with certain natural law. The phytocoenological process and principles have been described systematically (Wang et al., 1985a, 1987; Peng et al., 1985. 1993). The further analysis show that, in the successional process of community, the characteristics in each stage are expressed by the quantitative changes of dominant populations, which have different ecological characteristics in the community. It is helpful to deepen the understand of the successional principle to study the dynamics of main dominant populations in the successional process.

\section{SAMPLING FIELD AND COMMUNITY SUCCESSION PATTERN}

Dinghushan Biosphere Reserve is a member of the World's Biosphere Reserve Network organized by Man and Biosphere (MAB), United Nations Educational. Scientific and Cultural Organization (UNESCO). It is situated in middle part of Guangdong 
Province, South China, at $23^{\circ} 10^{\prime} \mathrm{N}$ and $112^{\circ} 35^{\prime}$. The altitude of the highest peak is $1000.3 \mathrm{~m}$. The rock is sandstone and shale belonging to the devonian period. The annual average temperature is $21.6^{\circ} \mathrm{C}$, the average temperature of the coldest month (January) is $12.0^{\circ} \mathrm{C}$. The annual average relative humidity is $80 \%$. The forest soil is lateritic red earth, $\mathrm{pH} 4.5 \sim 5.0$, the humus is rather rich. The principal climatic conditions are shown in Figure 1.

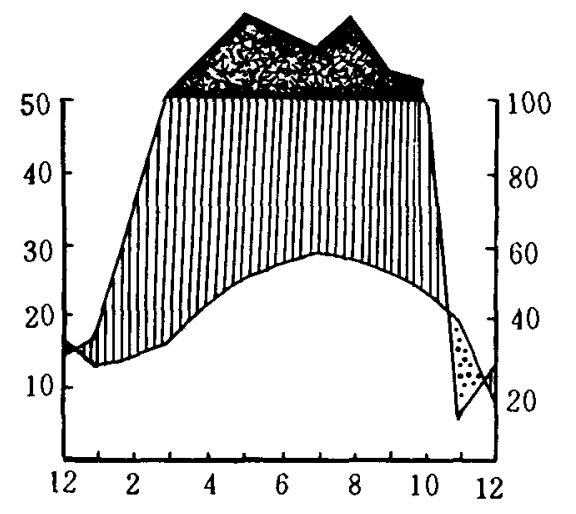

$23^{\circ} 10^{\prime} \mathrm{N} \quad 112^{\circ} 35^{\prime} \mathrm{E} \quad 150 \mathrm{~m}$

$1926.9 \mathrm{~mm} \quad 21.6^{\circ} \mathrm{C}\left(36.8^{\circ} \mathrm{C},-2{ }^{\circ} \mathrm{C}\right)$

Fig. 1 Climate of Dinghushan.

In the Reserve, there is a large natural forest, almost all of which is monsoon evergreen broad-leaved forest. This kind of forest is the typical zonal vegetation type in Low Subtropics (ECCV, 1980). also approximate to climax. There are varies forest communities with different development periods, which represent different stage in the successional process. So, it is an ideal experimental plot to study succession.

At the natural conditions, the main succession route of Dinghushan forest is following regular pattern: Pinus massoniana or other conifer species have high vitality in wasteland and grow very fast.

After they form a forest, however, the community has a simple structure with low coverage and high radiation indensity under the tree layer, temperature is high but humidity is low, and the temperature amplitude between day and night is large. Nevertheless, the growth of these species establish a better habitat for heliophytes, such as Castanopsis chinensis, Schima superba etc., to intrude and grow in Pinus massoniana forest. Under the canopy there are more layers and more individuals. As a result, Pinus massoniana population cannot regenerate naturally and then withers away. However mesophytes, such as Cryptocarya chinensis and Cryptocarya concinna, obtain the suitable habitat to develop. As the community becomes more complicated, heliophytes also wither out gradually. The community tends to climax which is dominated by mesophytes. This is the community succession principle in this area. The process is concluded as Figure 2. As Figure 2 shows, the community succession in each stage of succession are expressed by the change of each dominant population.

\section{METHOD}

\section{1 Time and spatial span}

This research is carried out in four typical communities which represent different stages of successional process of Dinghushan forest.

- Pinus massoniana community (Comm. 1)

- Pinus massoniana + Castanopsis chinensis + Schima superba community (Comm. 2)

- Cryptocarya fissa community (Comm. 3)

$\cdot 2 \cdot$ 
- Cryptocarya chinensis + Castanopsis chinensis + Cryptocarya concinna + Schima superba community (Comm. 4)

The dynamics of these communities have been studied basing on the surveys in 1955. 1982 and 1992, respectively (Wang et al., 1985a, 1987; Peng et al., 1985, 1993), the results indicated the changes of their successional stages in Figure 2:

successional stages

1 st

2nd

3 th

4 th

6 th vegetation types

coniferous forest

mised needle-broad-

leaved forest

dominated by conifer<smiles>[VH]</smiles>

mixed needle-broad-

leaved froest dominated

by heliophytes<smiles>[Y][Y]</smiles>

evergreen broad-leaved

forest dominated

by heliophytes

$\downarrow$

evergreen broad-leaved

forest dominated

by mesophytes

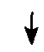

mesophyte community

(climax) representative communities

Pinus massoniana

community

Pinus massoniana-

Castanopsis chinensis-

Schima superba comm.<smiles>[Y]1[CH]C1</smiles>

Castanopsis chinensis-

Schima superba-Pinus

massoniana comm.

Cryptocarya fissa . community

$\downarrow$

Cryptocarya chinensis-

Castanopsis chinensis-

Cryptocarya concinna-

Schima superba comm.

Cryptocarya chinensis-

Cryptocarya concinna-

community

Fig. 2 Successional process of forest in Dinghushan.

Comm. 1 is in stage 1 (1955) and stage 2 (1992);

Comm. 2 is in stage 2 (1955) and stage 3 (1992);

Comm. 3 is in early stage 4 (1955) and late stage 4 (1992):

Comm. 4 is in stage 5 (1955) and stage 6 (1992).

- They have formed a successional spatial sere. It is further to uncover the successional mechanism to study the dynamics of dominant populations. Samples of every time are taken in twelve plots of $10 \times 10 \mathrm{~m}^{2}$.

\section{2 Measurement of niche breadth}

3. 2. 1 Shannon-Weiner Index proposed by Levins is used to determine the niche breadth of each dominant population in different time and space (Chapman, 1980; Cox. 1979: $\mathrm{Yu}, 1985)$. The niche breadth of population $i$ occupying $r$ resource conditions is

$$
B_{i}=-\sum_{j=1}^{r} P_{i j} \log P_{i j}
$$


$r$ means the amount of resource, here is number of sites sampled. $P_{i j}$ is the ratio of individuals of population $i$ in site $j$ to the sum of individuals in site $j$.

3. 2. 2 Method proposed by Colwell et al. (1972) is used to do the same thing. The relative weighted factor of resource condition $r_{j i}$ and the absolute weighted factor of resource condition $a_{j i}$ respectively are:

$$
\begin{gathered}
r_{j i}=\frac{\left(X_{j}-N_{i j}\right)\left[\ln \left(X_{j}-N_{i j}\right)-\ln \left(Z-y_{i}\right)\right]-\left[\sum_{i} N_{i j} \ln P_{i j}-N_{i j} \ln P_{i j}\right]}{\sum_{j}\left(X_{j}-N_{i j}\right) \ln \left(X_{j}-N_{i j}\right)-\left(Z-y_{i}\right) \ln \left(Z-y_{i}\right)} \\
a_{j i}=r_{i j} / \sum_{j} r_{j i}
\end{gathered}
$$

where $N_{i j}$ is the individual amount (abundance) of population $i$ in resource condition $j$ (site $j$ ). It indicates the resource tenure condition by population $i . X_{j}$ means the sum of individuals in site $j . Z$ means the sum of individuals in all sites. $P_{i j}=N_{i j} / X_{j}$.

\section{3. Measurement of population pattern}

3. 3. 1 The ratio of square deviation to mean value

$$
d_{i}=S_{i}{ }^{2} / X_{i}
$$

where $S_{i}{ }^{2}$ is the square deviation of individuals amount in each plot and $X_{i}$ is the mean value (Chapman, 1980; Cox, 1979). Formula (4) is used to determine the patterns of dominant populations spanning different space and time. The population follows Poisson distribution when $d$ is near to 1 , contagious distribution when $d$ is above 1 and uniform distribution when $d$ is below 1. The deviation degree can be measured with $t$ index:

$$
t=(d-1) / \sqrt{2 /(n-1)}
$$

3. 3. 2 Formula of negative binomial distribution

Negative binomial distribution is a distribution of two parameters. It originates from the expansion of algebric expression $P^{K}(1-q)^{K}$, where $P=K /(K+\mu), q=1-$ $P$. $K$ and $\mu$ are parameters of negative binomial distribution formula, where $\mu$ is average density of populations within the sampling plots, and $K$ is binomial index. The ecological meaning of $K$ is: When the population follows a random distribution, $K$ is negative: When the population follows an aggregated distribution, $K$ is positive and will decrease when the aggregated degree of population increases (Peng et al., 1984). The approximate value of $K$ can be calculated by

$$
\hat{K}=\bar{X}^{2} /\left(S^{2}-\bar{X}\right)
$$

The formula

$$
N \ln \left(1+X / \hat{K}_{i}\right)=\sum A_{x} /\left(\hat{K}_{i}+X\right)
$$

is used repeatedly to count the accuracy of $K$, where $A_{x}$ is the number of plots that contain individuals more than $X$. In a negative binomial distribution, the relative density of certain individual amount can be calculated by

$$
P(x)=[(X+K-1) /(K-1)] P^{K} q^{K}
$$

where $P(x) x N$ is the anticipated quadrat number.

\section{4 Measurement of Interspecific Relation (IR) \\ - 4 .}




\section{4. 1 The $X^{2}$ statistic value of interspecific association index}

The $X^{2}$ statistic value is used to determine the interspecific relations between the dominant populations in successional process (Wang et al., 1985b). For positive $X^{2}$ value, the lower value of $P$ (probability of the $X^{2}$ distribution) indicates the higher connection: If $0.01<P<0.05$, there is a positive IR in certain degree; if $P<0.01$, there is an obvious IR and there must be some obvious ecological relative commection except for accidental factors; if $P>0.05$, the populations distribute almost independently though there are some connection between the populations. A negative $X^{2}$ value means a negative IR.

3. 4. 2 Interspecific similarity index

$$
C_{i k}=1-\frac{1}{2} \sum_{j=1}^{r}\left|P_{i j}-P_{k j}\right|=\sum_{j=1}^{r} \operatorname{Min}\left(P_{i j}, P_{k j}\right)
$$

Formula (9) is used to measure the interspecific niche overlap between the dominant populations in successional process, where $C_{i j}$ indicates the niche overlap of population $i$ and population $j$ in $r$ plots (Peng et al. , 1990).

\section{RESULT AND DISC̈USSION}

\section{1 Change of Niche Breadth (NB)}

The niche breadth changes of five dominant populations in successional seres are recorded in Figure $3 \sim 9$ and Table 1.

4. 1. 1 The NB of Pinus massoniana population reduces in the successional process, and wither away in the broad-leaved stage which dominated by heliophytes. This reveals its pioneer characteristics. Pinus massoniana population is replaced fast in early period (from Pinus forest to needle broad leaved mixed forest) and has a high mortality in the late (from needle-broad leaved mixed forest to monsoon evergreen broad-leaved forest dominated by heliophytes).

4. 1. 2 The NBs of heliophytes, such as Castanopsis chinensis and Schima superba, gradually widen with the successional course, has a highest value at the stage of monsoon evergreen broadleaved forest dominated by heliophytes. This displays the feature of these populations as pioneer species of climax community. Their NBs increase fast within the stage from Pinus forest to needle-broad-leaved mixed forest, and slow within the stage from needle-broad mixed forest to monsoon evergreen-broad-leaved forest dominated by heliophytes. Then, the NB drop fast, but some individuals still remain in the forest. This indicates that these two pioneer species are also the constructors of climax community.

4. 1.3 The NBs of mesophytes, such as Cryptocarya chinensis and Cryptocarya concinna, enlarge gradually since the middle stage of needle-broad-leaved forest. They have the highest increasing speed in stage of monsoon evergreen broad-leaved forest dominated by heliophytes (Comm. 3), and tend to be stable in the stage of monsoon evergreen broad-leaved forest dominated by mesophytes. This showes the traits of these populations as zonal climax species. 


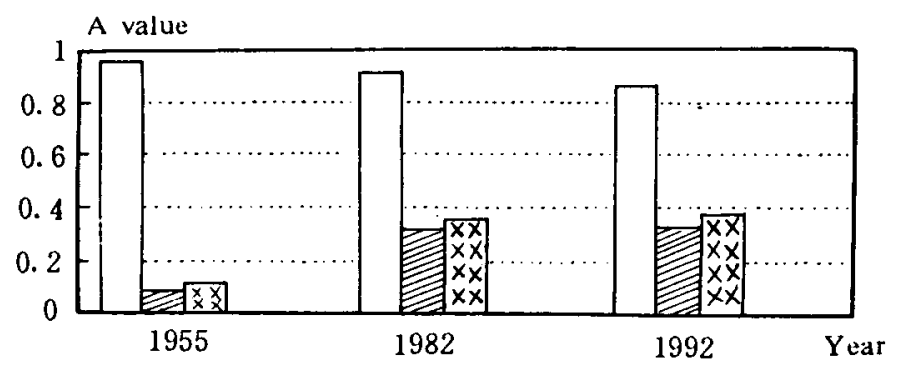

Fig. 3 Time sere in Comm. 1

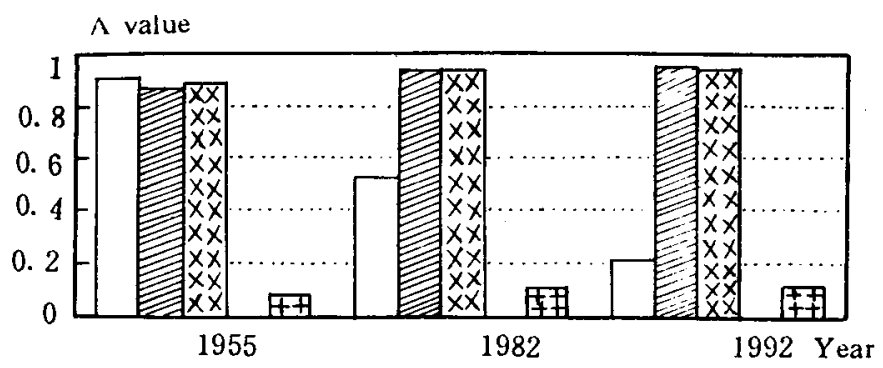

Fig. 4 Time sere in Comm. 2
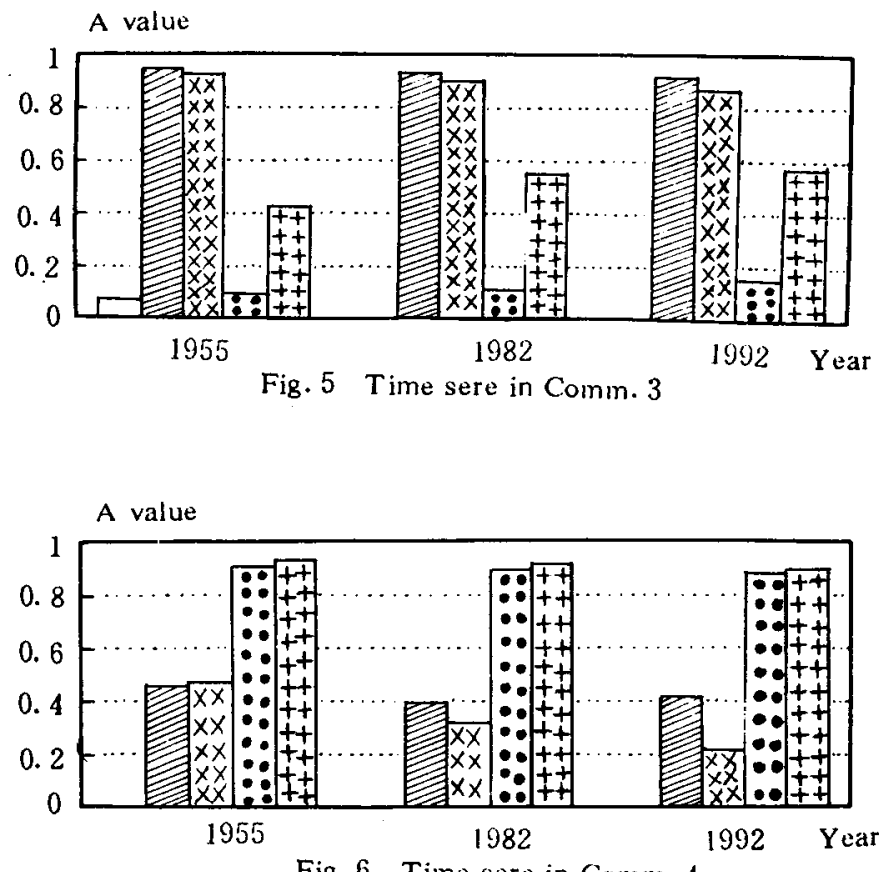

Fig. 6 Time sere in Comm. 4 


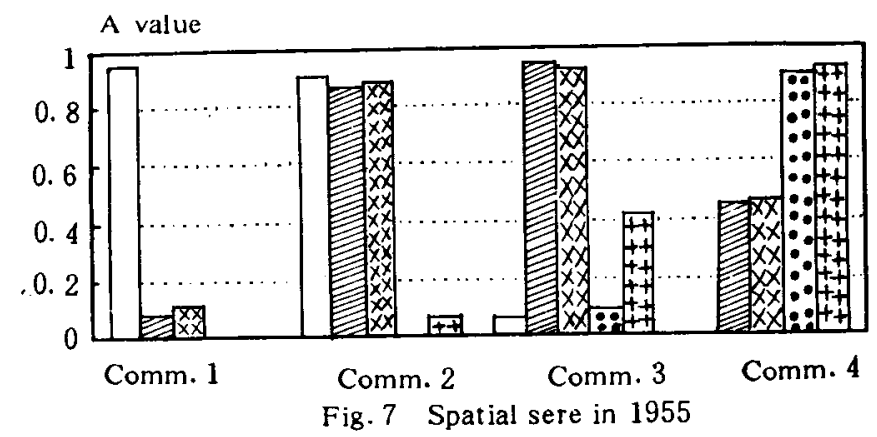

A value

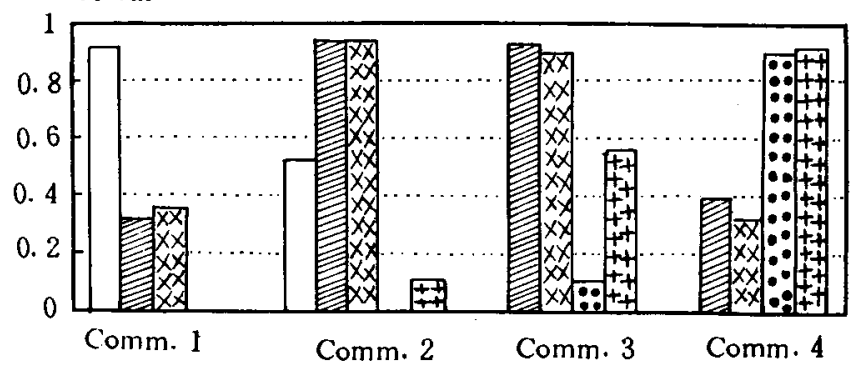

Fig. 8 Spatial sere in 1982

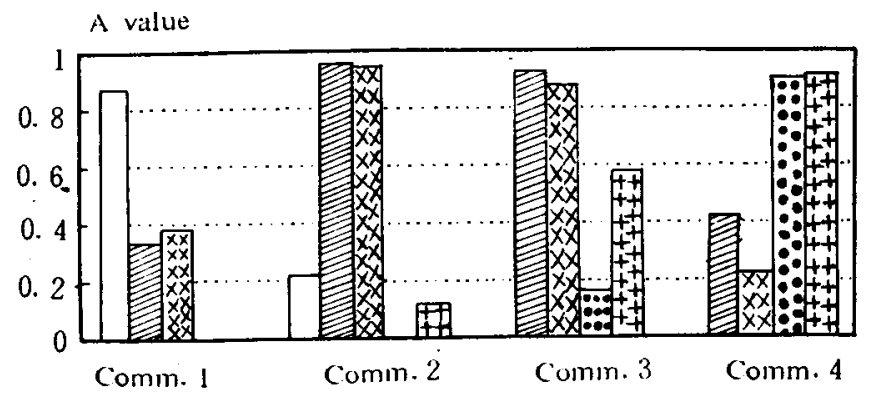

Fig. 9 Spatial sere in 1992

\begin{tabular}{|c|c|}
\hline & Pinas masixuina \\
\hline & Castanup sis chinen sis \\
\hline 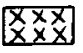 & Schima superba \\
\hline$[\because \because:]$ & Cryplucarya chinensis \\
\hline$\left[\begin{array}{l}+ \pm+7 \\
+ \pm+\end{array}\right]$ & Cryptocarya concinna \\
\hline
\end{tabular}


Table 1 Niche Breadth changes of dominant populations in successional sere.

\begin{tabular}{|c|c|c|c|c|c|c|c|c|c|}
\hline \multirow{2}{*}{$\begin{array}{l}\text { Chrono- } \\
\text { sequences }\end{array}$} & \multicolumn{3}{|c|}{1955} & \multicolumn{3}{|c|}{1982} & \multicolumn{3}{|c|}{1992} \\
\hline & A & B & $\mathrm{C}$ & A & $\mathrm{B}$ & $\mathrm{C}$ & $\mathrm{A}$ & $\mathrm{B}$ & $\mathrm{C}$ \\
\hline \multicolumn{10}{|c|}{ Pinus massoniana } \\
\hline Comm. 1 & 0.96 & 0.98 & 0.60 & 0.92 & 0.93 & 0.54 & 0.87 & 0.90 & 0.49 \\
\hline Comm. 2 & 0.91 & 0.90 & 0.55 & 0.53 & 0.71 & 0.30 & 0.22 & 0.23 & 0.11 \\
\hline Comm. 3 & 0.08 & 0.09 & 0.02 & 0 & 0 & 0 & 0 & 0 & 0 \\
\hline Comm. 4 & 0 & 0 & 0 & 0 & 0 & 0 & 0 & 0 & 0 \\
\hline \multicolumn{10}{|c|}{ Castanopsis chinensis } \\
\hline Comm. 1 & 0.09 & 0.11 & 0.03 & 0.32 & 0.33 & 0.14 & 0.33 & 0.41 & 0.16 \\
\hline Comm. 2 & 0.87 & 0.88 & 0.55 & 0.94 & 0.97 & 0.58 & 0.95 & 0.97 & 0.60 \\
\hline Comm. 3 & 0.95 & 0.98 & 0.52 & 0.93 & 0.94 & 0.56 & 0.92 & 0.94 & 0.53 \\
\hline Comm. 4 & 0.46 & 0.50 & 0.21 & 0.40 & 0.47 & 0.16 & 0.42 & 0.46 & 0.11 \\
\hline \multicolumn{10}{|c|}{ Schima superba } \\
\hline Comm. 1 & 0.12 & 0.13 & 0.04 & 0.36 & 0.37 & 0.14 & 0.38 & 0.40 & 0.18 \\
\hline Comm. 2 & 0.89 & 0.91 & 0.54 & 0.94 & 0.96 & 0.57 & 0.94 & 0.97 & 0.56 \\
\hline Comm. 3 & 0.93 & 0.96 & 0.56 & 0.90 & 0.94 & 0.53 & 0.87 & 0.90 & 0.50 \\
\hline Comm. 4 & 0.47 & 0.44 & 0.22 & 0.32 & 0.40 & 0.15 & 0.22 & 0.28 & 0.11 \\
\hline \multicolumn{10}{|c|}{ Cryptocarya chinensis } \\
\hline Comm. 1 & 0 & 0 & 0 & 0 & 0 & 0 & 0 & 0 & 0 \\
\hline Comm. 2 & 0 & 0 & 0 & 0 & 0 & 0 & 0 & 0 & 0 \\
\hline Comm. 3 & 0.10 & 0.12 & 0.03 & 0.12 & 0.18 & 0.06 & 0.16 & 0.27 & 0.09 \\
\hline Comm. 4 & 0.91 & 0.95 & 0.56 & 0.90 & 0.94 & 0.54 & 0.89 & 0.92 & 0.54 \\
\hline \multicolumn{10}{|c|}{ Cryptocarya concinna } \\
\hline Comm. 1 & 0 & 0 & 0 & 0 & 0 & 0 & 0 & 0 & 0 \\
\hline Comm. 2 & 0.08 & 0.11 & 0.03 & 0.11 & 0.16 & 0.05 & 0.12 & 0.17 & 0.08 \\
\hline Comm. 3 & 0.43 & 0.56 & 0.28 & 0.56 & 0.67 & 0.39 & 0.58 & 0.70 & 0.40 \\
\hline Comm. 4 & 0.93 & 0.98 & 0.58 & 0.92 & 0.95 & 0.55 & 0.90 & 0.94 & 0.52 \\
\hline
\end{tabular}

A, B. C mean values measured by Formula (1), (2), (3), respectively.

4. 1. 4 Conclusion: The index of NB reflects the position of a population in a community or the resource possessing condition of the populations. In the process of succession, because of its adapting to poor environment and growing fast, Pinus massoniana took the resource of community firstly. In the early period (Comm. 1), it occupied about $90 \%$ of the whole niche. Then, heliophytes, such as Castanopsis chinensis and Schima superba, intruded into the community and developed continuously till to occupy the largest space and most resource. As a result, Pinus massoniana, which had a preference for sunlight, disappeared rapidly. And mesophytes, which are more shade-tolerant, began to develop till they occupied resoure most. Obviously, it is the restriction of resource, especially light resource, that determines the NB change of each population in a community. On the other hand, the NB value of different kind of populations are effective to indicate the community's successional stage.

\section{2 Development of patterns of dominant populations}

The patterns of five dominant populations spanning different time and space of successional process are recorded in Table 2.

4. 2. 1 Pinus massoniana population follows uniform distribution after constructing a forest because of its partly artificial planting. As its amount of individuals grow, the 
population tends to follow aggregated distribution in the early period of succession because the seeds disseminate around their mother trees. With the succession advancing and broad-leaved species intruding constantly, Pinus massoniana cannot regeneration naturally, and then die out gradually. The population follows random distribution in later period because the death of individuals is generally random. and withers away completely in the middle of succession.

Table 2 Pattern changes of dominant populations in successional sere.

\begin{tabular}{|c|c|c|c|c|}
\hline \multirow{2}{*}{$\begin{array}{l}\text { Chrono- } \\
\text { sequence }\end{array}$} & \multicolumn{2}{|c|}{1982} & \multicolumn{2}{|c|}{1992} \\
\hline & $\mathrm{K}$ & d & $\mathbf{K}$ & $\mathrm{d}$ \\
\hline \multicolumn{5}{|c|}{ Pinus massoniana } \\
\hline Comm. 1 & 14.22 & uniform & 8.61 & uniform \\
\hline Comm. 2 & 9.84 & random & $<0$ & random \\
\hline Comm. 3 & 1 & / & / & / \\
\hline Comm. 4 & 1 & 1 & 1 & / \\
\hline \multicolumn{5}{|c|}{ Castanopsis chinensis (heliophyte) } \\
\hline Comm. 1 & 2.22 & aggregated & 3.68 & aggregated \\
\hline Comm. 2 & 8.85 & aggregated & 12.11 & aggregated \\
\hline Comm. 3 & 11.43 & aggregated & 3.21 & aggregated \\
\hline Comm. 4 & $<0$ & random & 1.12 & aggregated \\
\hline \multicolumn{5}{|c|}{ Schima superba (heliophyte) } \\
\hline Comm. 1 & 1.89 & aggregated & 2.61 & aggregated \\
\hline Comm. 2 & 6.47 & aggregated & 6.43 & aggregated \\
\hline Comm. 3 & 7.44 & aggregated & 2. 43 & aggregated \\
\hline Comm. 4 & $<0$ & random & $<0$ & random \\
\hline \multicolumn{5}{|c|}{ Cryptocarya chinensis (mesophyte) } \\
\hline Comm. 1 & 1 & / & 1 & I \\
\hline Comm. 2 & $/$ & $/$ & 2.43 & aggregated \\
\hline Comm. 3 & 3.48 & aggregated & 4.28 & aggregated \\
\hline Comm. 4 & 4. 78 & aggregated & 4.87 & aggregated \\
\hline \multicolumn{5}{|c|}{ Cryptocarya concinna (mesophyte) } \\
\hline Comm. 1 & 1 & / & / & / \\
\hline Comm. 2 & / & / & 1.02 & aggregated \\
\hline Comm. 3 & 5.44 & aggregated & 4.63 & aggregated \\
\hline Comm. 4 & 3.07 & aggregated & 2.68 & aggregated \\
\hline
\end{tabular}

4. 2. 2 The heliophytes, such as Castanopsis chinensis and Schema superba, are all from the mixed forest nearby, and then have orientation. So, when they intrude in Pinus massoniana forest in the early time, they form an aggregated distribution pattern. And the degree of aggregation increases in developing period. In the process of succession toward the mesophytic monsoon evergreen broad-leaved forest. the populations tend to follow a random distribution because individuals die out randomly.

4. 2.3 An environment fit for mesophytes is founded after heliophytes intrude in Pinus massoniana forest. The mesophytes, such as Cryptocarya chinensis and Cryptocarya concinna, are also from the zonal monsoon evergreen broad-leaved forest, and then have orientation. The mesophytes tend to form a contagious distribution pattern at first. Then their contagion intensity increases in the developing period because the scope of seed dissemination is controlled by mother trees, and decreases in the process of succession toward mesophytic monsoon evergreen broad-leaved forest because of the self thin- 
ning.

4. 2. 4 Conclusion: In the successonal process of vegetation in low subtropical area, the population patterns change in different routes because of their different properties. The pattern alternation process of each population is consistent with the alternation process of its quantitative dynamics (Wang Bosun et al., 1987). This indicates some relation between pattern and abundance of a population.

\section{3 Alteration of interspecific relations between dominant populations}

Alteration of interspecific relation between dominant pqpulations spanning different stages of successional process are recorded in Table 3.

Table 3 Changes of interspecific relationship of dominant populations in succession sere.

\begin{tabular}{|c|c|c|c|c|c|c|c|c|}
\hline \multirow[t]{2}{*}{ Species * } & \multicolumn{4}{|c|}{$X^{2}$ value for IR } & \multicolumn{4}{|c|}{ Niche overlap value-C } \\
\hline & Comm. 1 & 2 & 3 & 4 & Comm. 1 & 2 & 3 & 4 \\
\hline & & & & & & & & \\
\hline $1+2$ & 1.01 & 3.50 & 0 & 0 & 0.12 & 0.81 & 0 & 0 \\
\hline $1+3$ & 0.80 & 3.07 & 0.07 & 0 & 0.08 & 0.69 & 0 & 0 \\
\hline $1+4$ & 0 & 0 & 0 & 0 & 0 & 0 & 0 & 0 \\
\hline $1+5$ & 0 & 0.09 & 0.02 & 0 & 0 & 0.29 & 0 & 0 \\
\hline $2+3$ & 1.28 & 3.75 & 3.95 & 3.00 & 0.55 & 0.90 & 0.85 & 0.20 \\
\hline $2+4$ & 0 & 0 & 0.90 & 0.65 & 0 & 0 & 0.65 & 0.20 \\
\hline $2+5$ & 0 & 0.85 & 1.42 & 1.20 & 0 & 0.35 & 0.71 & 0.32 \\
\hline $3+4$ & 0 & 0 & 0.88 & 0.55 & 0 & 0 & 0.45 & 0.13 \\
\hline $3+5$ & 0 & 0.80 & 1.22 & 1. 18 & 0 & 0.32 & 0.61 & 0.30 \\
\hline \multirow[t]{2}{*}{$4+5$} & 0 & 1.10 & 1. 78 & 2.64 & 0 & 0.38 & 0.80 & 0.96 \\
\hline & & & & & & & & \\
\hline $1+2$ & 1.91 & 3. 97 & 0 & 0 & 0.21 & 0.88 & 0 & 0 \\
\hline $1+3$ & 1.60 & 4.06 & 0 & 0 & 0.13 & 0.72 & 0 & 0 \\
\hline $1+4$ & 0 & 0 & 0 & 0 & 0 & 0.02 & 0 & 0 \\
\hline $1+5$ & 0.70 & 0.19 & 0.01 & 0 & 0.06 & 0.31 & 0 & 0 \\
\hline $2+3$ & 1. 31 & 3.85 & 3.95 & 3.04 & 0.65 & 0.90 & 0.85 & 0.16 \\
\hline $2+4$ & 0 & 0 & 0.95 & 0.55 & 0 & 0 & 0.65 & 0.11 \\
\hline $2+5$ & 0 & 0.88 & 1.66 & 1.50 & 0 & 0.38 & 0.75 & 0.23 \\
\hline $3+4$ & 0 & 0 & 0.98 & 0.50 & 0 & 0 & 0.55 & 0.16 \\
\hline $3+5$ & 0 & 0.80 & 1.26 & 1.00 & 0 & 0.27 & 0.60 & 0.28 \\
\hline $4+5$ & 0 & 1.30 & 1.98 & 2.23 & 0 & 0.38 & 0.89 & 0.90 \\
\hline
\end{tabular}

* The number of species: 1. Pinus massoniana: 2. Castanopsis chinensis; 3. Schima superba; 4. Cryptocarya chinensis; 5. Cryptocarya concinna.

4. 3. 1 The interspecific association and niche overlap between Pinus massoniana population and heliophyte populations are higher and higher in early stage, lower and lower in the stage from needle-broad-leaved mixed forest to broad-leaved forest.

4.3. 2 The two values between heliophyte populations and mesophyte populations are high in evergreen broad-leaved forest stage, and reduce in late stage.

These results reveal the feature of Pinus massoniana and heliophytes populations as $\cdot 10 \cdot$ 
pioneers. On the other hand, they also show that, the cycle and regeneration of mature community cause the community organization uneven and mosaic, and this makes the heliophyte populations remain some amount in the late stage of succession.

4. 3. 3 The interspecific association and niche overlap between mesophyte populations and Pinus massoniana population are relatively low in the stage of needle-broad-leaved forest, and drop to zero in the stage when the heliophytes become dominant in the evergreen broad-leaved forest. This indicates that these two kind of species have quite different demand for habitat. This result also shows the feature of mesophyte populations as climax populations of the forest.

4. 3. 4 Conclusion: The dynamics of interspecific associations and niche overlaps between different populations depict the degree and features of these populations existing together and sharing resource together. On the other hand, they also depict the competition process between the populations and similarity of each population's requirement for the habitat.

\section{REFERENCES}

Chapman S B (translated by Yang Hanxi), 1980. Methods in Plant Ecology. Science Press (in Chinese)

Colwell R K, Futuyma D J, 1972. On the measurement of niche breadth and overlap. Ecology, $52(4)$ : $567 \sim 576$

Cox G W (translated by Jiang Youxu), 1979. Experiment Bulletin of General Ecology. Science Press (in Chinese)

Edition committee of China Vegetation, 1980. Chinese Vegetation. Science press (in Chinese)

Knapp R (eds.) (translated by Song Yongchang), 1984. Vegetation Dynamics. Science Press . (in Chinese)

Peng Shaolin, Wang Bosun, 1984. Analysis of Dinghushan forest communities I Population patterns. Tropical and Subtropical Forest System, (2):24 37 (in Chinese)

Peng Shaolin, Wang Bosun, 1985. Analysis of Dinghushan forest communities. V. Nonlinear succession sere. Tropical and Subtropical Forest System, (3) $: 25 \sim 31$ (in Chinese)

Peng Shaolin, Wang Bosun, 1990. Niche overlaps of dominant populations in Dinghushan forest communities. Tropical and Subtropical Forest System, (6) :19 28 (in Chinese)

Peng shaolin, Wang Bosun, 1993. Succession in Dinghushan forest communities. Journal of Tropical and Subtropical Forest System. (Testing 2) : 34 42 (in Chinese)

Solomon M E, 1976. Population Dynamics. Edward, Arnold, London

Wang Bosun, Peng Shaolin, 1985a. Analysis of Dinghushan forest communities V Linear succession sere. Acta of Sun Yat-sen University (Nàtural Sciences). (4) : 75 80 (in Chinese)

Wang Bosun, Peng Shaolin, 1985b. Measurement techniques of interspecific relation on low subtropical evergreen broad-leaved forest I Exploration and correction of the measurement formula of interspecific relation. Acta phytoecologica et geobotanica sinica, 9 (4):274 285 (in Chinese)

Wang Bosun, Peng Shaolin, 1987. Dynamic of dominant populations in Dinghushan. Acta Ecologyca Sinica. 7 (3) : 214 221 (in Chinese)

Wang Zhuhao et al., 1982. Vegetation 'in Dinghushan Reserve. Tropical and Subtropical Forest System. (1) : 77 141 (in Chinese)

West D C, Shugart H H, Botkin D B, 1981. Forest Succession. Spinger-Verlag. New York, Inc.

Yu Shixiao, 1985. A study on niche breadths and overlaps of dominant species in Dinghushan Cryptocarya community. Tropical and Subtropical Forest System, (3):32 41 (in Chinese) 